

\section{INDICE}

\section{ÁMBITOS PERSONALES PERSONAL ÁMBITOS}

Las revistas satíricas sevillanas en el primer tercio del siglo XX y sus dibujantes

Sevillian satirical magazines in the first third of the 20th century and their cartoonists

J. Carlos Méndez Paguillo

\section{ARTÍCULOS ARTICLES}

El humor en la publicidad radiofónica. La marca de la Cadena SER a través de las promos de Ortega Humour in radio advertising. The brand of the Cadena SER through the Ortega's advertisements

Javier de Sola Pueyo, Ana Segura Anaya, Antonia Isabel Nogales-Bocio

La narrativa transmedia en la publicidad: el caso de "LEGO"

Transmedia narrative in advertising: the case of "LEGO"

Jaime Humberto Caldera Chacón, Gloria Olivia Rodríguez Garay

Nuevos relatos híbridos en el cine de ficción español. El caso de Entre dos aguas de Isaki Lacuesta New hybrid stories in Spanish fiction cinema. The case of Entre dos aguas by Isaki Lacuesta

Manuel Blanco Pérez

$60-73$

La serie de TV 'Medici': Entre historia, memoria y producto comercial

The TV series 'Medici': between history, memory and comercial product

Pamela Giorgi, Irene Zoppi

Realidad y ficción en el discurso informativo. Crímenes como inspiración para proyectos audiovisuales en España Reality and fiction in informative discourse. Crimes as inspiration for audiovisual projects in Spain 
Relatório Macbride: Releitura à luz de ameaças ao direito à comunicação nas plataformas digitais MacBride report: re-reading in light of threats to the right to communication on digital platforms Lilian Bartira Santos Silva, Carla Azevedo de Aragão, Nelson De Luca Pretto

La violencia de género en Twitter según Vox en las elecciones autonómicas de Andalucía Gender violence on Twitter according to Vox in the regional elections of Andalusia Sergio Luque Ortiz, Mónica Cano Alarcón 116-133 Estructura mediática china: una aproximación al caso de China Central Television (CCTV) Chinese media structure: an approximation to the case of China's Central Television (CCTV) 


\title{
Nuevos relatos híbridos en el cine de ficción español. El caso de Entre dos aguas de Isaki Lacuesta
}

\author{
New hybrid stories in Spanish fiction cinema. The case of Entre dos aguas by \\ Isaki Lacuesta
}

\author{
Manuel Blanco Pérez \\ Universidad de Sevilla | Calle Américo Vespucio, 27, 41092 Sevilla | España | \\ http://orcid.org/0000-0003-1159-4679 | mblancoperez@us.es
}

Fechas | Recepción: 11/10/2020 | Aceptación: 05/11/2020 | Publicación final: 15/01/2021

\begin{abstract}
Resumen
En el Festival de San Sebastián de 2018 el film ganador fue Entre dos aguas (Lacuesta, I. 2018). El cineasta catalán construye un film de ficción que, sin embargo, tiene también mucho de autorreferencial y biográfico y, por tanto, de periodístico (todos los actores son amateurs que se interpretan a sí mismos en el film), y utiliza buena parte de una cierta estética visual documental periodística. Esos actores, a su vez, ya habían sido protagonistas 12 años antes de otro film del cineasta, La leyenda del tiempo (2006), sin embargo, el valor de la aportación de Lacuesta reside en que esos personajes interpretan una vida que no vivieron, pero que fácilmente podrían haber vivido, visto el contexto de su mundo. En su propuesta, lo real se mezcla con la ficción en un film donde ambas resultan igual de verosímiles. El análisis de esta pieza nos permitirá, además, identificar muchas de las características del nuevo cine de hibridación contemporáneo, como la cohabitación con la objetividad, la deontología del creador, la ruptura de las fronteras entre la ficción y la no ficción, o el uso de una cierta ucronía ${ }^{1}$ dentro del guion
\end{abstract}

\begin{abstract}
At the 2018 San Sebastian Festival the winning film was Entre dos aguas (Isaki Lacuesta, 2018). The Catalan filmmaker constructs a fiction film that, however, is also very much self-referential and biographical and therefore journalistic (all the actors are amateurs who play themselves in the film), and uses a good part of a certain journalistic documentary visual aesthetic. These actors, in turn, had already been protagonists for 12 years before another film by the filmmaker, $L a$ leyenda del tiempo (2006). However, the value of Lacuesta's contribution lies in the fact that these characters play a life they did not live, but could easily have. In his proposal, reality is mixed with fiction in a film where both are equally plausible. The analysis of this footnote will also allow us to identify many of the characteristics of the new contemporary hybrid cinema, such as the cohabitation with objectivity, the deontology of the creator, the breaking of the frontiers between fiction and non-fiction, or the use of a certain ucrony within the script that inserts his characters (with varying degrees of luck) into their natural environment. We intend to analyze
\end{abstract}

\section{Forma de citar:}

Blanco Pérez, M. (2021). Nuevos relatos híbridos en el cine de ficción español. El caso de Entre dos aguas de Isaki Lacuesta. Ámbitos. Revista Internacional de Comunicación, 51, pp. 60-73. doi: 10.12795/Ambitos.2021.i51.04 
que inserta a sus personajes (con suerte dispar) en su medio natural. Pretendemos analizar cómo este nuevo lenguaje fílmico hibridado permite un conocimiento diferente del entorno, con las implicaciones de todo tipo que ello supone.

Palabras clave: cine documental, Isaki Lacuesta, géneros cinematográficos, audiovisual, narrativa fílmica, documentalismo periodístico. how this new hybrid film language allows a different knowledge of the environment, with all the implications that this implies.

Keywords: documentary filmmaking, Isaki Lacuesta, film genres, audiovisual, film narrative, journalistic documentalism

\section{INTRODUCCIÓN}

Los límites entre la realidad y la ficción, en la corta historia del cine, siempre han sido muy difusos. Pero, además, en tiempos recientes, se vienen desarrollando propuestas cinematográficas que, sin ser absolutamente inéditas, sí que han sido llevadas a nuevos territorios donde el cine está obligado a reformular parte de su ontología. En concreto analizaremos el caso del filme Entre dos aguas (Lacuesta, 2018) por ser paradigmático de ese lenguaje hibridado y que se caracteriza por una propuesta alambicada entre la ficción y que parte de los recursos visuales del periodismo audiovisual.

A ello hay que añadir el gran trabajo que se hace previamente con el elenco actoral: ninguno de ellos es profesional y, Lacuesta, como si de un reportero se tratara, trata de sacar el potencial narrativo de gente anónima que, con sencillez, narra su propia vida en su entorno. Por tanto, el lenguaje fílmico usado, hibridado, es una suerte de ucronía narrativa con sus propias vidas, herramienta narrativa ésta de cierta tradición, pero que nos interesa analizar por cómo el autor encaja ese corpus en una realidad socio-política tan particular como la andaluza Bahía de Cádiz.

\section{EL CINE DOCUMENTAL Y LA FICCIÓN EN LA ERA ANALÓGICA}

La separación entre realidad y ficción siempre ha sido débil en el mundo del cine. Ya desde la considerada primera obra de la historia en el cine periodístico y documental Nanook of the north (Robert Flaherty, 1922), en que se nos muestra la vida de un esquimal en su cotidianidad con su familia, la obra presenta particularidades contextuales en el protagonista que necesariamente significa que se trató de una puesta en escena (Gutiérrez-San Miguel, 2015). Hay varios ejemplos, pero destacaremos uno: la construcción de varios iglús para recrear el efecto de que se rueda desde dentro de uno solo de ellos, cosa imposible pues, por las limitaciones técnicas de la época, no existía película sensible como para tal rodaje en condiciones de baja luminosidad.Durante el siguiente medio siglo, las películas de ficción rodadas al inicio de la década de 1920 llegaron a ser curiosidades de museo -con sus vestidos, peinados, etc.- pero Nanook, el esquimal conservó una pasmosa validez, una vitalidad muy poco afectada por el tiempo. (Barnouw, 1996, p. 46)

${ }^{1}$ [Ou chronos], del griego: "no tiempo". Guarda cierta semejanza con la formulación de utopía de Tomás Moro. Una ucronía es un no-lugar en el tiempo, aquello que no pasó, pero podía fácilmente haber pasado. 
El cine y su dimensión documental (periodística) nacen prácticamente juntos, al punto que de las primeras cosas que se filmó en celuloide fue, precisamente, unos obreros saliendo de una fábrica, en las afueras de Lyon a comienzos del año 1895, por los hermanos Lumière. La cámara se colocó delante de la puerta y filmó la realidad. Se rodaron escenas cotidianas de la vida diaria porque, en aquel momento, el medio era el mensaje. El 28 de diciembre de 1895 en París, en Boulevard des Capucines, los Lumière proyectan al público sobre una gran pantalla un ferrocarril en movimiento hacia la cámara. Habla Noël Burch sobre los ataques de pánico en el público (pensaban que serían arrollados por la locomotora), y cuenta que hubo cuatro versiones de ese proto-filme, una de las copias, al parecer, desaparecida. Todo en lo que el propio Burch llama-rá "etapa de plenitud del modo de representación Primitivo" (Burch, 1987, p. 33).

Tras ese impacto inicial de la representación de la locomotora, ruedan obras de teatro tratando, en el fondo, de documentar una representación artística (una concepción aristotélica de arte, parecido al concepto de "espejo" en Stendhal, que estaba aún lejos de crear una narrativa propia cinematográfica, pero que ahonda en estas lindes siempre débiles entre la realidad y la ficción). Pero bien temprano, el británico George Albert Smith, casi por casualidad, comienza a hilvanar trozos diferentes de metrajes diversos y a juntarlos ensamblados. Además, usa distintos tipos de planos (al inicio copiados del arte pictórico) y crea el concepto de "primer plano" que, además, insertó dentro de un mismo encuadre de un plano general. Empezaba, poco a poco, a vertebrarse un lenguaje fílmico con sintaxis propia. Que llegará a su máximo esplendor tanto en la Unión Soviética (Eisenstein y otros), como en la República de Weimar (Fritz Lange y otros), algunas de cuyas obras siguen siendo hoy clásicas.

Tras el periodo de entreguerras y la Segunda Guerra Mundial, es especialmente reseñable la corriente humanista del Neorrealismo italiano, que realizó un gran énfasis en codificar lo realista en unos términos muy específicos: será la primera vez que se cree cine de ficción con actores no profesionales de teatro (y/o cine): personas anónimas que cuentan su propia vida interpretándose a sí mismas. Ello crea unos límites fronterizos aún más débiles, muy visibles por ejemplo en Paisà (Roberto Rossellini, 1946). Si bien, era algo que ya se había explotado en el formato cortometraje, como Silent Village (1943) del británico Humphey Jenning. Es justo reseñar que buena parte de la creación del Hollywood de la postguerra (en tanto industria) será analizado por una cada vez más extensa literatura científica, como el abundante trabajo de Kristin Thompson (2001) y David Brodwell $(1995,1997)$, así como trabajos que lo vinculan específicamente a la aparición de la televisión (Cascosa-Virino, 2005), entre muchos otros avata-res de entre los que hubo de pasar como medio.

También hay, sin apartarnos de la relación que el cine tiene con la interpretación de lo real, reseñables trabajos que profundizan en la visión de género del cine (Tello-Díaz, 2016), o el paradigmático trabajo sobre lo real en el cine de Armendáriz que llevó a cabo Sánchez-Noriega (2012). Ya en 2002, Kiarostami estrena el film Ten. La película, muy espartana en la realización, fue rodada con una videocámara casera de $16 \mathrm{~mm}$ colocada en el salpicadero de un coche: un plano continuo -pero editado- en que se recogen diez historias, ordenadas desde la 10 a la 1. La protagonista es siempre la misma chica joven divorciada, y al automóvil se subirá su hijo (con quien discute), así como otra chica y mas personas: juntas hablan de la visión femenina de la sociedad, debaten sobre las familias, etc. En el cine de Kiarostami 
Los términos "realismo" y "neorrealismo" se cuelan por todos los párrafos que se escriben sobre las películas de este director $y$, a decir verdad, lo cierto es que tampoco faltan motivos para ello. Es más; podría decirse con toda legitimidad que la búsqueda de la máxima contigüidad entre la realidad y su representación es el motor esencial que dirige la puesta en escena de sus películas. (Heredero, 1995, p. 81)

Así mismo, nos interesa no solo la hibridación generada a modo de ficción con tintes realistas, sino, también al revés, cuando lo realista comienza a penetrar en un corpus netamente ficcional. Hablamos por ejemplo de El espíritu de la colmena (Víctor Erice, 1973), en la toma (luego dividida en dos planos por el montaje) en que se cuela la mira-da de la actriz Ana Torrent (entonces niña aún, con siete años), mirando a la pantalla de cine y en que Erice dice "no previsto" y que, por tanto, posee valor documental. Del mismo modo que la mirada de dicha actriz en escena de la escuela:

Es un primer plano no previsto en la escritura del guion ni más tarde provocado o sugerido por la preparación de la filmación. [...] La cámara se topó de bruces con algo que no esperaba, una de las más puras erupciones del milagro del asombro de que hay noticia, la que expulsó, con la elocuencia de sus ojos enormes absortos y boquiabiertos, de su turbación ante lo que veía en la pantalla la niña Ana. [...] Luis Cuadrado disparó la cámara y atrapó al vuelo uno de los más hermosos instantes del cine, hecho con un brote de realidad robada a la vida. (FernándezSantos, 2007, p. 251)

De ese instante, recogido sin estar previsto por el guion, y obtenido por puro capricho del azar en la lente, el escritor Francisco Umbral dirá: "Esos ojos, Dios, esos atroces ojos. Mira como desde el fondo grave, puro y tenso de la infancia"2. Por último, también creemos pertinente reseñar el magnífico trabajo sobre el concepto de enunciación del género cinematográfico, en el que trabajaron los investigadores Gutiérrez-San Miguel y González-Sánchez (2013).

\section{HIPÓTESIS Y OBJETIVOS}

Serán varias las hipótesis y los objetivos que nos marcamos. En primer lugar, reflexionaremos sobre el cine de Lacuesta, que aborda, gracias a su herramienta narrativa de hibridación, una nueva subjetividad que ofrece, en su película, una relación compleja y sugerente entre la realidad y la reconstrucción de la misma.

En segundo lugar, este tipo de cine aborda cuestiones de gran envergadura y amplitud socio política, y las coloca en situación de dependencia con respecto a otra suerte de condicionantes de tipo cotidiano mucho más intrascendentes, por ello reflexionaremos sobre los componentes sociopolíticos del entorno donde se desarrolla la acción, pues la bahía de Cádiz ha sufrido una fuerte desindustrialización en las últimas décadas, y es pasto de una visión mediática que la vincula, casi por inercia, al desempleo, el narcotráfico, el menudeo. Pese a ello, la belleza del entorno es sublime.

\footnotetext{
${ }^{2}$ Madueño, J. J.: "Isaki Lacuesta: 'me gusta el concepto de España y creo en él'”. ABC Andalucía. 29 de abril de 2016. Rescatado de: https://bit.ly/3fMPhFz
} 
La presente investigación realizará, para ello, un estudio fílmico de la hibridación del lenguaje de ficción y el documental en el film Entre dos aguas (Isaki Lacuesta, 2018). El cineasta catalán construye una película de ficción que, sin embargo, posee un lenguaje hibridado, y lo es porque emplaza a todos los actores a interpretarse a sí mismos en el cronotopos fílmico.

Esos actores (ninguno de los cuales es profesional, recordemos), a su vez, ya habían sido protagonistas 12 años antes de otro film del cineasta, La leyenda del tiempo. Isaki Lacuesta, pertenece a una generación de cineastas catalanes que se iniciaron en el oficio con una exultante juventud en el cambio de siglo, con su ópera prima Cravan vs cravan (2002) ganó el premio al Director Revelación del Festival de Sitges, además de Mejor Película en el Festival de cine de Vitoria, entre otros.

Aunque La leyenda del tiempo (2006) y Entre dos aguas (2018), pueden verse de manera independiente, es obvio que guardan muchos vasos comunicantes. La primera narra la vida de un joven gitano de 13 años (con una voz prodigiosa) y una enfermera japonesa que llega a San Fernando, la localidad natal de Camarón, para aprender a cantar flamenco, pero que se muestra incapaz de completar su propósito.

Además de varios personajes, son varios los aspectos que coinciden en ambas piezas. Para empezar, ese naturalismo del lenguaje fílmico que emplea, que lo aleja de los estándares de cine blockbuster: la cámara suele estar siempre al hombro, con planos realizables por un operador a pie (no hay planos rodados con grúa, steadicam, estabilizadores, raíles ni tomas aéreas de helicóptero/dron), la dirección de fotografía es parca y la iluminación muy naturalista, claroscura, que remite a una primigenia escuela pictórica flamenca (Rembrandt), lo cual consigue un discurso crudo, muy limpio y, por tanto, con una estética que lo acerca más al discurso de cine documental periodístico "realista", si bien:

El amplio abanico mediático que configura lo que va del documental a la ficción ha ido generando distintas formas de "representación de lo real", de manera que nuestra manera de describir ese "real" ha estado siempre ligada a las propias herramientas utilizadas para su descripción y análisis. (Sucari, 2013, p. 46)

Preguntado sobre su voluntad de retratar la realidad a través de un lenguaje hibridado entre la ficción y el documental, el propio director afirmará que:

Son dos cosas distintas y válidas, siempre y cuando no engañes al espectador. La ficción puede ser fascinante para comprendernos y el documental también. Son dos impulsos que están en el ser humano desde las cuevas. Por un lado, la idea de crear mitos y, por otro lado, la de saber qué está pasando en las tribus de al lado. Tiene que existir y tenemos la necesidad de ambas cosas.

Ahora bien, si estos personajes están basados en varias personas reales es, en realidad, una licencia creativa hacia una suerte de ucronía. El propio Lacuesta, en una entrevista concedida a El País, luego de ganar el Festival de San Sebastián 2018, afirma que "hemos hecho una película con un guion trabajado; sin embargo, hay momentos en que esa ficción no está predeterminada, no sabíamos qué iba a ocurrir". 
El origen de esta hibridación del documental con la ficción, es algo que hace ya más de una década supieron vislumbrar Josetxo Cerdán y Josep Maria Català:

Si para la ficción, la llegada del sonoro había supuesto un cambio fundamental, para el documental el cambio vino más bien impulsado por la aparición de los equipos ligeros de rodaje. Esta circunstancia tecnológica creó un estilo de documental, más inmediato y menos formalista, que acabó por convertirse, con la ayuda de la televisión, en la forma documental canónica que aún ahora perdura en el imaginario del medio. Hoy estamos ante un nuevo cambio, el cambio de la digitalización. (Catalá y Cerdán, 2008, p. 7)

El autor Isaki Lacuesta, con su propuesta de hibridación, nos arrastra a un entorno muy particular que, a la luz de esta herramienta, ofrecerá nuevos hallazgos -cinematográficos, sociales- sugerentes, sobre los que reflexionaremos.

\section{MARCO CONCEPTUAL: EL CINE DOCUMENTAL Y DE FICCIÓN COMO REFLEJO DE LO REAL}

\subsection{Proliferación de un nuevo cine que reinterpreta lo real: raíces populares}

A finales de los años 90 del pasado siglo surgen una serie de autores que suponen un cambio en el perfil profesional: son cineastas vocacionales, que pasaron por la Universidad y, al mismo tiempo, se han curtido como profesionales del audiovisual en los más variados lugares. Presentan trabajos con un marcado carácter híbrido y una ruptura radical entre los géneros que, hasta ese momento, se daban por cerrados en lo periodístico y mediático (y no tanto en lo académico), como son el documental y la ficción.

(...) esa cuestión de la divisoria entre documental y ficción, [es] algo que viene siendo habitual reivindicación en la tradición de los films que podemos definir, ya hoy, como una línea de formación, esa que parte de Innisfree (José Luis Guerín, 1989) y El sol del membrillo (Víctor Erice, 1992). (Cerdán, 2007, p. 212)

Pero, si hacemos prospección, hay una raíz mucho mas antigua, una frontera desbordada entre el documental y ficción que puede ya encontrarse en los años 40 en nuestro país, en el documental fotográfico Spanish Village. Allí, Eugene Smith pasó semanas inmortalizando esa aldea extremeña sumida en la miseria de la postguerra española. Pero la inmortalización era una puesta en escena: instó a madres a vestir de primera comunión a sus niños (que portaban vestidos blancos inmaculados pero, incomprensiblemente, caminaban descalzos) y hasta la Guardia Civil aparece retratada con rostros desencajados (Smith los obligó a mirar al sol, y a contener la mirada sin pestañear, hasta lograr la expresión gestual precisa que él buscaba)... preguntado por ello, Smith dirá "estos hombres son actores: su papel consiste en ser ellos mismos" (Lugón 2010: 168). Es la misma lógica, llevado al documental cinematográfico que, apenas unos diez años antes, inspiró el film Las Hurdes / Tierra sin pan (Luis Buñuel, 1933).

Muchas décadas después, la película documental Asaltar los cielos (1996), sobre Ramón Mercader, el asesino español de León Trotsky, consigue una permanencia en carteleras por seis meses y hubo gran aceptación entre los exhibidores del género documental. Tras ello: 
En 1997, José Luis Guerín realiza Tren de sombras, en el año 1999, Jordà, junto a Núria Villazán, dirige Monos como Becky/ Mones com la Becky, Guerín es también el responsable de En construcción (2001), mientras que el mismo año Pablo García realiza Fuente álamo: la caricia del tiempo, en 2002 llega a las pantallas Cravan vs. Cravan, de Isaki Lacuesta; y en 2003 De niños / De nens, de nuevo Jordà, y 200 kms, de un grupo de recién graduados que se autodenominan Discusió 14. (Cerdán, 2005, p. 357)

El cine de autor de estos años vendrá marcado, siguiendo la tradición francesa del cine naturalista ontológico, por un enraizamiento profundo en lo popular. Entendiendo esto como una muestra identitaria de reconstrucción y alterconstrucción desde los márgenes:

Si no se come igual en una choza que en un palacio -decía Engels- forzosamente tampoco la idea (y sus concreciones) de la belleza, la verdad, la soledad, el amor, el destino, el dolor, la esperanza, etc... serán iguales para esos dos estómagos. Por lo tanto, los universales no existen como tales, sino que existen encarnados en hombres concretos y en ideas concretas. (Orihuela, 2004, p. 31)

Josetxo Cerdán vincula la obra de Lacuesta a una lógica primitivista que, sostiene, se vertebra "en dos líneas que evidentemente se complementan: la de una relación primaria, tosca, no elaborada con el entorno, y la de una vuelta a unos hipotéticos orígenes de salvajismo" (Cerdán, 2007: 217). Ese vínculo con lo popular, de alguna manera, está presente en ciertos vectores de la propia sociedad en que se desarrolla, pues:

El cine de Lacuesta es primitivista y, por lo tanto, opositor respecto a la cultura masiva, pero también a la elitista como cultura restrictiva. (...) Lacuesta asume una posición donde lo popular está contenido en sus fuentes de inspiración, en el perfil de sus personajes, en las músicas que utiliza, en la concepción materialista de sus films y, en definitiva, en todas esas opciones de puesta en forma. (Cerdán, 2007, p. 239)

Se produce, por tanto, un emplazamiento de ruptura en la posición del cineasta que, junto con cierta proliferación de la industria cinematográfica, propicia en torno al cambio de siglo un nuevo cine, que aún hoy es objeto de atención mas fuera de nuestras fronteras que dentro.

\subsection{Hibridaciones de género mixto: cine de ficción y documental}

Estas zonas de interferencias que se han ido creando en los últimos años significan la apertura de nuevos paradigmas en la forma y función de los discursos de la imagen, así como de nuevos modelos de representación que sugieren un gran impulso de nuevas prácticas. (Sucari, 2013, p. 16)

En el caso que nos ocupa, Entre dos aguas, que en modo alguno puede ser considerado un falso documental, sí que ahonda en esa línea débil que siempre ha separado el documental de la ficción, y lo hace mediante una estructura vehicular con mucha personalidad: el artilugio narrativo que ha creado Lacuesta (el guion es obra del propio Lacuesta y de Isa Campo con Fran Araújo), y que consiste en llevar al extremo la ucronía del entorno, y de los propios personajes/personas. Es decir, Israel Gómez 
Romero, que interpreta el personaje de Isra, ha debido interpretar lo que él (persona y personaje a la vez), sentiría estando en el presidio, siendo repudiado por su mujer y casi no reconocido por su hija menor: hechos todos ellos que nunca han sucedido en la vida real del actor.

El director aborda sus proyectos a partir de figuras míticas de una evidente radicalidad en una forma de enfrentarse al mundo, principalmente en lo que el mundo espera de ellos. (Cerdán, 2007, p. 216)

En cambio, varias de las imágenes han sido filmadas de la realidad, como las imágenes del parto de Rocío, mujer en la vida real del actor Israel Gómez y que también aparece en la película interpretando el papel de la esposa de Isra.

Un concepto mucho más representativo, por tanto, es el de "efecto referencial", que resulta útil como instrumento analítico. Y tiene que ver con la mencionada institucionalización de modalidades de recepción para las diversas tipologías de relato que configuran lo que podemos denominar el Occidente del sentido. (Carrera y Talens, 2018, p. 50)

Al fin, "Realmente no existen los géneros totalmente 'puros', el grado de 'pureza' viene dado por oposición al grado de 'hibridación' o mezcla de un género con otros afines. Los géneros necesitan poder ser reconocidos" (González-Sánchez y Gutiérrez-San Miguel, 2013).

\section{METOdOlOgía}

En este trabajo esbozaremos una suerte de fotografía fija, de diagnóstico acerca del carácter hibridado en la obra del cineasta Isaki Lacuesta y, muy específicamente, centrados en su obra Entre dos aguas (2018). Para ello vamos a aplicar una metodología deductiva para aterrizar de lo general a lo particular, y así anclar de manera más sugerente nuestro estudio. Asimismo, dividiremos el análisis en varias partes diferenciadas, para poder cubrir todo el espectro de la realidad estudiada.

El método empleado se sustentará, por un lado, en el análisis cinematográfico desde el punto de vista semiótico del texto fílmico (Marzal y Gómez Tarín, 2007), poniendo de relieve aquellos elementos que vinculan la obra en su corpus narrativo con el concepto de ficción y su codificación audiovisual de lo real. Y, por otro lado, en el análisis fillmico estructural que proponen Jacques Aumont y Marie Michel basado, principalmente, en el análisis del film como relato (Aumont y Michel, 1990) quien, como es sabido, elabora su propuesta a partir de las investigaciones lingüísticas de LéviStrauss, y, además de él: "las influencias mas evidentes ejercidas sobre el desarrollo del análisis textual proceden sin duda de Umberto Eco, Roland Barthes y, claro está, Christian Metz" (Aumont y Michel, 1990: 98). Al fin, proponemos un tipo de herramienta semiótica trasversal (Blanco Pérez, 2020a, p. 23) que, si bien:

Necesariamente ha de beber del análisis cinematográfico stricto sensu, debemos añadir las implicaciones que, desde la ideología como causa, propician que veamos el reflejo en la propia pantalla: a veces como guiños, a veces como metáforas visuales más o menos veladas $y$, en ocasiones, como partes de un discurso (textual, visual, quinético, cromático o de cualquier 
otro) que, sumados entre sí, nos ofrecen unos detalles de la obra que contienen mucha intencionalidad de fondo.

Eventualmente acudiremos también al trabajo de Ramón Carmona (2010) quien nos propone una suerte de reconstrucción en el estudio de un film (y que, a menudo, él extrapola a todo el cine en su conjunto) a partir de fragmentos mínimos extraídos de un metraje de obra concreta, descontextualizada. Por último, interpretaremos también la película en tanto estudio cultural, siguiendo la metodología de Manuel Palacio:

Metodológicamente, ha prosperado una técnica interdisciplinaria de análisis, que sitúa al texto fílmico en su contexto histórico y cultural. De este modo, los estudios culturales hispanos en lugar de observar los aspectos estéticos o artísticos del film establecen una mirada que privilegia la contemplación del texto como un documento cultural. (Palacio, 2007, p. 71)

Procederemos, en primer lugar, a hacer un análisis de personajes y, seguidamente, tendremos ocasión de reflexionar, a nivel de contenido narrativo, sobre aquellos aspectos ajenos -o no- a las personas/ personajes protagonistas. Con respecto a los análisis de los espacios abordaremos aquellos lugares por los que discurre la película y que puedan dar una idea clave, tanto en interiores como exteriores, de su propuesta de emplazamiento (del indoeuropeo [-plat], de donde deriva el léxico castellano "plazo" -tiempo- y "plaza" -lugar-). Con respecto al análisis del sonido analizaremos su propuesta rítmica desde la dimensión sonora (voz en of, banda sonora original, etc.). Por último, tendremos también ocasión de tratar el tipo de fuentes y materiales fílmicos con que se ha construido la narración.

\section{ENTRE DOS AGUAS (2018) DE ISAKI LACUESTA}

Como avanzamos antes, el personaje protagonista es Isra, quien se relaciona con otros en una escalada de despropósitos que le llevan a un final tan presumible como inevitable. El crítico Ezequiel Obregón lo analiza así:

Que Israel Gómez Romero haya obtenido el premio al Mejor Actor por interpretarse a sí mismo es todo un signo de lo que ocurre con el cine en la actualidad, una de las formas del arte que ha tenido que reformular su ontología frente a la proliferación de otros tantos medios vinculados a la exhibición de la propia vida, además de la construcción de la realidad que propone el periodismo.

En cuanto a los personajes coadyuvantes, se nos antoja trascendental ver cómo evolucionaron desde su precuela La leyenda del tiempo (2006) para constatar que el medio es, en esta historia, otro actor más de primer orden que interrelaciona con las personas que lo habitan, provocando la salvación en algunos (gracias al colchón de la familia, su humanidad) y la condena de otros (el menudeo del narcotráfico, la vida al margen de la ley, la cárcel, la soledad).

El concepto clave sobre el que pivota toda la película es la relación Isra-mundo. Isra es el protagonista absoluto de la cinta y realiza el viaje del héroe en el film que arranca con su estancia en el presidio y su breve permiso penitenciario para asistir al parto de su última hija. La vida en prisión no es fácil, 
obligado -como está- a pensar en la relación con su madre (que fue quien lo denunció a la policía) y unos grupos evangelistas a los que rara vez sigue con convicción. Su salida al mundo real se revela compleja. Nadie le quiere dar trabajo y, cuando por mediación de su hermano Cheíto, consigue faena de guarda en un depósito de vehículos decomisados, apenas puede fantasear con una vida de lujo lejos de la precariedad más absoluta. Su mujer no solo no lo apoya, si no que lo expulsa de casa y no le permite entrar hasta que no se "rehabilite", cosa que rara vez puede hacer nadie sin oficio ni casa. Se instala en una vieja chabola de pescadores en primera línea de playa que, cuando sube la marea, inunda su morada (y su vida).

Es una de esas películas rodadas de tal manera que parece más un reality show que una película. La historia fluye de tal manera que parece que no hay guion, que los personajes hablan por ellos, que es una secuencia de escenas en las que, por casualidad había cámaras con ellos.

En el film existen, por tanto, dos personajes: Isra y el entorno de Isra, aunque con menciones a otros familiares pues, es claro que el entorno en el que se desplaza lo biográfico es hacia lo familiar. Su alter ego, su fiel escudero es su hermano "feo" que, sin embargo, se ha convertido en este tiempo en todo un prohombre dentro del sistema: trabaja en la marina, tiene tres niñas, una bonita familia modesta donde todos son felices y alberga un sueño nocturno de ser pequeño empresario (con el dinero de la marina quiere "ponerle una panadería" a su mujer). Ese contrapeso entre el Isra que quiere su entorno y el Isra superviviente de sí mismo será buena parte del mecanismo narrativo que haga andar la historia.

Con respecto al análisis de contenido narrativo, es vital valorar aquellos aspectos ajenos o no a las personas/ personajes protagonistas. El personaje de Isra deambula una realidad que deberá aprehender en un sentido más íntimo: la de adaptarse a la vida precaria de un trabajo mal remunerado con nula capacidad de realización o la de volver al narcotráfico que ya le ocasionó varios años de presión (denunciado por su propia madre, que temía perderlo en una de las noches eternas del narco) y que en la práctica significó la separación de sus hijas (la pequeña no lo conoce apenas).

Con respecto a los análisis de los espacios, conviene reseñar que hay una visión muy arcaica del territorio y el hogar del modesto barrio de la Casería (San Fernando, Cádiz): marinero, añejo y zíngaro (prácticamente todos los protagonistas son de etnia gitana), es íntimo en el hogar pero, al mismo tiempo, aprovecha la construcción de tres rascacielos de estética dudosa junto al mar, en ese mismo barrio, en cuyas azoteas la gente bien de la ciudad queda para hacer negocios (casi siempre vinculados con el narcotráfico). El personaje de Isra, por tanto, transita de su mundo bajo al mundo alto. EI mundo bajo es el mar (la desangelada casucha de pescadores que se inunda cuando sube la marea), el descampado, que es donde fuma y bebe con sus amigos y familia. Y en el mundo de las alturas, el segundo espacio, que es donde coquetea con el lado oscuro al margen de la ley, con esta gente-bien que le propone volver a las andadas del narco-tráfico.

Los temas que se abordan en el film son, por debajo de la vida de Isra, en apariencia insignificantes. En realidad, más que un debate entre la vida en sociedad o la vida al margen de la ley (debate que parece que Isra tuviera ya resuelto desde hace tiempo), hay cierta necesidad de huida: fantasear entre 
la chatarra subiéndose a un helicóptero del depósito de viejos cacharros donde fue temporalmente trabajador.

Por otro lado, el empleo del elemento sonoro es significativo. Si bien "el impacto que una dirección de fotografía tiene en una obra, asî como el peso de la narración o el trabajo actoral, hacen que esta otra dimensión sonora siempre pase -de manera casi inconsciente- a un segundo plano" (Blanco Pérez, 2020b, p. 126). En esta película de Isaki Lacuesta, en cambio, el sonido es un elemento de primer orden. El tema compuesto por el músico Kiko Veneno (uno de los iconos de la contracultura andaluza), conecta este film con un submundo que no está presente, pero se intuye desde el comienzo hasta el final: ese mundo no tanto marginal como marginado, de clases desfavorecidas que malviven en un entorno turístico de una belleza incomparable. Una metáfora de Camarón que, sin embargo, no representa la realidad de nadie en la Casería por mucho que todos allá quisieran ser como él. Junto al mencionado tema de Kiko Veneno, encontramos el trabajo del catalán Raül Refree que, junto a elementos sonoros diegéticos y ambientales, se vuelve un elemento determinante para completar el sentido hibridado (cinematográfico y documental) que, también en lo sonoro, se presenta a caballo entre ambos.

Como antes se avanzó, el rodaje fílmico se ha alternado con uso de material de archivo (procedente de La leyenda del tiempo) pero, no lo olvidemos, también de fotografías personales de los propios protagonistas: ahondando en este lenguaje mestizo que posee toda la obra y que, en este particular, se usa como refuerzo narrativo, a modo de bordón musical, para remarcar pequeños detalles que, sin embargo, permiten al receptor reflexionar sobre asuntos como el paso del tiempo, o lo sutil e instantáneo -al tiempo que azaroso- del entorno. Como, por ejemplo, cuando Isra descorre una cortina de la humilde casa en La leyenda del tiempo (2006) y luego, doce años más tarde, el Isra de Entre dos aguas (2018) descorre esa misma cortina, y cómo ambos planos se superponen en el metraje como una invitación a la reflexión del ubi sunt, el beatus ille o, simplemente, un eslabón más, otra parada conceptual, en el viaje del héroe.

Y, en medio de todo ello, la idea recurrente de viaje acuoso, de río eraclitiano, de presencia de agua como líquido amniótico que abriga a todos y cada uno de sus personajes que hacen la vida cara al mar.

\section{RESULTADOS Y CONCLUSIONES}

La investigación hasta aquí expuesta plantea tres conclusiones, son las que siguen. En primer lugar, el concepto de nueva subjetividad en el cine y como ésta se narra en la propuesta de película de género hibridado entre la ficción y el documental que nos ocupa. Como se ha analizado previamente, no codifica lo real adaptándolo a una deontología periodística (aunque buena parte de su estética así pareciera sugerirlo): su estructura cinematográfica es de una honestidad impecable. En esta película, el punto de vista es prácticamente único, el del protagonista Isra o, al menos, es el punto de vista que predomina sobre las otras subtramas que, a su vez, siempre dependen -directa o indirectamente- del propio Isra. Este enfoque, sin embargo, no atenúa ni merma su estatus, ni el valor de documento de lo real. Por tanto, siendo una propuesta de cine ficción posee elementos de documental íntimo, biográfico, de autorretrato de un tiempo y de una parte del sur del sur, no resulta descabellada ni supone una contradicción con respecto a la tradición de cine de ficción, simplemente es una evolución 
en la que se es más consciente de sus posibilidades expresivas llevando a los actores/personas por otros derroteros ucronísticos.

En segundo lugar, este tipo de cine no renuncia, en la mayoría de los casos, a abordar cuestiones de gran envergadura y calado socio político, pero las coloca en situación de dependencia con respecto a otra suerte de condicionantes de tipo más cotidiano y, en apariencia, intrascendentales. Siendo así, el cine de Lacuesta es íntimo y en él se transfigura una representación de lo cotidiano. Incluso algo tan banal como un tatuaje del protagonista, se convierte en una diatriba entre Isra versus mundo de Isra (lo que se espera de él), siempre en conflicto permanente.

En tercer lugar, la ficción y no ficción en este film íntimo se suman a los rasgos anteriores como una tendencia común, donde se entremezclan sin pudor. Un recurso que desdibuja las fronteras entre lo que es documental y lo que es cine de ficción. Lo interesante de esta tendencia, que hasta hace no tanto era poco más que una excentricidad fílmica, es cómo abre y posibilita nuevos caminos que anteriormente eran impensables. Esta propuesta fílmica implica no solo dejar un testimonio de lo real, sino ofrecer hechos e información socio política e histórica, buscando, además, sumergirse más profundamente en los subtemas y cuestiones sociales. Difuminar esas fronteras entre la ficción y el documental, encontrar un lenguaje hibridado hasta hacer ambas esferas indistinguibles, no deja de ser otro recurso narrativo más para alcanzar ese objetivo, presente en todo el film, de enriquecer ese discurso.

Por último, y como conclusión general, comprobamos cómo la necesidad de etiquetar, conceptualizar y encajonar las fronteras del trabajo de ficción con el documental se enfrenta al hecho de que, en la práctica, el lenguaje hibridado es tremendamente rico y variado, heterogéneo y sugerente. De ahí la dificultad y quizá la ineficacia de querer establecer una tipología cerrada para el film de ficción y/o documental, íntimo y biográfico que es Entre dos aguas. Ello se comprueba en su propio desarrollo a lo largo del tiempo (visto en paralelo, además, con La leyenda del tiempo): en su proceso de avance hacia una radicalización (acudir a la raíz del contexto) y generalización de la subjetividad. Este film es un ejemplo de película que se libera de ataduras autoimpuestas y demanda una mayor creatividad clasificatoria, una propuesta de hibridación donde no existan prejuicios y las leyes del mercado cinematográfico sean flexibles para no amputarle una dimensión conceptual tan rica como difícil de etiquetar.

Precisamente porque, como dijera Montalbán, "una mentira sirve, a veces, mejor que una verdad para explicar la verdad misma", máxime cuando tanto la mentira como la verdad son, en este film, igual de verosímiles.

\section{Referencias}

Aumont, J. \& Michel, M. (1990). Análisis del film. Paidós Ibérica.

Barnouw, E. (1996). El documental: historia y estilo. Gedisa.

Blanco Pérez, M. (2020a). Nuevo Cine Andaluz. Comunicación Social.

Blanco Pérez, M. (2020b). Cine y Semiótica. Universidad de Salamanca. 
Bordwell, D. \& Thompson, K. (1995). El arte cinematográfico: una introducción. Paidós.

Bordwell, D.; Thompson, K. \& Staiger, J. (1997). El cine clásico de Hollywood: estilo cinema-tográfico y modo de producción hasta 1960. Paidós Ibérica.

Burch, N. (1987). El tragaluz infinito. Cátedra.

Carmona, R. (2010). Cómo se comenta un texto fílmico. Cátedra.

Carrera, P. y Talens, J. (2018). El relato documental. Cátedra.

Cascosa-Virino, C. C. (2005). La televisión llega a Hollywood: una aproximación a los dra-máticos llevados al cine. Ámbitos. Revista Internacional de Comunicación, 13-14, pp. 91-108. http://dx.doi.org/10.12795/ Ambitos.2005.i13-14.07

Catalá, J. M. y Cerdán, J. (2008). Después de lo real. Pensar las formas del documental, hoy. Archivos de la filmoteca, 57. Generalitat Valenciana.

Cerdán, J. (2005). Documental y experimentalidad en España: crónica urgente de los últimos veinte años, en: Torreiro, C. \& Cerdán, J. (Eds.): Documental y vanguardia. Cátedra.

Cerdán, J. (2007). Una nube es una nube, en: Cerdán, J. \& Torreiro, C. (eds.): Al otro lado de la ficción. Trece documentalistas españoles contemporáneos. Cátedra.

Cerdán, J. \& Torreiro, C. (2007). Al otro lado de la ficción: trece documentalistas españoles contemporáneos. Cátedra.

Eco, U. (1964). Apocalittici e integrati. Bompiani.

Fernández-Santos, Á. (2007). La mirada encendida. Debate.

González-Sánchez, J. F. \& Gutiérrez San Miguel, B. (2013). El concepto de transversalidad en la enunciación del género cinematográfico. Ámbitos. Revista Internacional de Comunicación, 22. http://dx.doi. org/10.12795/Ambitos.2013.i22.09

Gutiérrez-San Miguel, B. (2015). Estudio evolutivo del lenguaje narrativo, desde los primeros documentales a las transmedias, en Fernández-Guerra, V. (ed.), Revisitando el cine documental: de Flaherty al webdoc. (pp. 207-244), Cuadernos Artesanos de Comunicación, 83. Latina.

Heredero, C. F. (1995). Abbas Kiarostami. Más allá de la realidad; más cerca de lo real. Nosferatu. Revista de cine, 19, 80-87. http://hdl.handle.net/10251/40941

Lugón, O. (2010). El estilo documental. De August Sander a Walker Evans 1920-1945. Universidad de Salamanca.

Marzal-Felici, J. y Gómez-Tarín, F. J. (2007). Metodologías del análisis del film. Edipo.

Orihuela, A. (2004). La voz común: una poética para recuperar la vida. Tierradenadie Ediciones.

Palacio, M. (2007). Estudios culturales y cine en España. Comunicar, revista científica de Comunicación y Educación, 29, v. XV. 69-73.

Sánchez Noriega, J. L. (2012). Compromiso y creatividad artística en el realismo de Montxo Armendáriz. Ámbitos. Revista Internacional de Comunicación, 21, 186-206. http://dx.doi.org/10.12795/Ambitos.2012.i21.10

Sucari, J. (2013). El documental expandido: pantalla y espacio. UOC.

Tello-Díaz, L. (2016). La 'mirada femenina': estereotipos y roles de género en el cine español (1918-2015). Ámbitos. Revista Internacional de Comunicación, 34. http://dx.doi.org/10.12795/Ambitos.2016.i34.05

Thompson, K. (2001). Storytelling in the New Hollywood: Understanding classical narrative technique. Harvard University. 


\section{Filmografía citada}

Buñuel, L. (1933). Las Hurdes / Tierra sin pan.

Eisenstein, S. (1925). El acorazado Potemkin.

Erice, V. (1973). El espíritu de la colmena.

Guerín, J. L. (1997). Tren de sombras.

Jenning, H. (1943). Silent Village.

Lacuesta, I. (2002). Cravan vs Cravan.

Lacuesta, I. (2006). La Leyenda del tiempo.

Lacuesta, I. (2015). Murieron por encima de sus posibilidades.

Lacuesta, I. (2018). Entre dos aguas.

Lang, F. (1927). Metrópolis.

Rossellini, R. (1946). Paisà.

Semblanza del autor

Manuel Blanco (Sevilla, 1980) es Licenciado en Filología Hispánica (US) y Doctor en Literatura y Comunicación (US). Docente universitario desde 2008, ha impartido clases de Comunicación, Cine, Fotografía y Literatura en las Universidades de Cádiz y Huelva, en la actualidad es profesor de la Facultad de Comunicación de la Universidad de Sevilla. Como investigador es autor de una docena de artículos científicos de impacto y varios libros académicos, entre los que destacan las obras: Cine y Semiótica (Universidad de Salamanca, 2020) y Nuevo cine andaluz (Comunicación Social, 2020). Autor de varias obras literarias y exposiciones fotográficas: Diario Disidente de Nueva York (2005), 28 Rue Levert (2008), el film documental Al sur del sur (2018) es su ópera prima en cine como director y guionista (XV SEFF y 45 Festival Iberomericano de Cine, actualmente en Filmin.es). 